\title{
A study on analytical framework to breakdown conditions among data quality measurements
}

\author{
N. Deshai ${ }^{1 *}$, G.P Saradhi Varma ${ }^{2}$, S.V. Ramana ${ }^{3}$ \\ ${ }^{1}$ Assistant Professor, Department Information Technology, S.R.K.R Engineering College, Bhimavaram, Andhra Pradesh, India \\ ${ }^{2}$ Professor, Department Information Technology, S.R.K.R Engineering College, Bhimavaram, Andhra Pradesh, India \\ ${ }^{3}$ Associate Professor, Department Information Technology, S.R.K.R Engineering College, Bhimavaram, Andhra Pradesh, India \\ *Corresponding author E-mail: deshain000@gmail.com
}

\begin{abstract}
The point of this survey is to feature issues in information quality research and to talk about potential research chance to accomplish high information quality inside an association. The survey received deliberate writing audit technique in view of research articles distributed in diaries and gathering procedures. Here built up an audit technique in light of particular subjects, for example, ebb and flow inquire about territory in information quality, basic measurements in information quality, information quality administration model and approaches and information quality evaluation strategies. In light of the audit methodology, here select pertinent research articles, concentrate and amalgamation the data to answer an examination questions. The survey features the headway of information quality research to take after its genuine application and talk about the accessible hole for future research. Research territory, for example, association's administration, information quality effect towards the association and database related specialized answers for information quality overwhelmed the early years of information quality research. Be that as it may, since the Web is presently occurring as the new data source, the rising of new research regions, for example, information quality evaluation for web and huge information is unavoidable. This audit additionally recognizes and talks about basic information quality measurements in association, for example, information fulfillment, consistency, exactness and convenience. Likewise think about and feature holes in information quality administration model and procedures. This survey is critical to feature and break down restriction of existing information quality research identified with the current needs in information quality, for example, unstructured information sort and enormous information.
\end{abstract}

Keywords: Data quality, Data quality management model, assessment methods, database, organization.

\section{Introduction}

Accomplishing high information quality has turned into a critical component in overseeing information inside an association. Having high information quality could help an association to plan better business methodology and divulge business design for basic leadership. Disappointment in giving high information quality to the association have brought different issues, for example, false choice because of inaccurate information, high cost of operation and absence of consumer loyalty [1]. In addition, the expanding quantities of information accessible today with obscure quality levels added difficulties to ideally dissect and make utilization of information that are applicable to the association.

High information quality has been characterized as an information that is fit for utilize and ready to meet the purposed set by information client [1]- [4]. This definition plainly recommended that nature of information is very needy to the setting of information use and collaborations to the client needs, capacity to utilize and capacity to get to information. Along these lines, in information quality evaluation and change process, investment of information clients and other information partners that are include amid information passage, information handling and information investigation is essential. Different strategies have been proposed to evaluate information quality from the setting of information clients and other information partners including utilizing study, and survey.

Scientists received reviews and poll to gather necessities and desires from information client, information passage staff and other information partner. Selection of studies and polls is essential so as to characterize information quality properties and information quality measurements to accomplish high information quality inside its unique circumstance. Factual strategies, for example, relationship investigation are then used to distinguish connection amongst traits and arrange the properties into information quality measurements for instance information culmination, information consistency, information exactness and information opportuneness. Then again, discoveries of the investigation help specialist to distinguish reason for information quality issues and accordingly, recommendation on information quality change can be made.

The talk gave in this survey is constrained just to the current proposition in information quality research that can be straightforwardly actualized in any association with particular purposes, for example, business. In doing this examination, research articles that proposed estimation measurements for information quality and information quality structure without appropriate appraisal strategy. By doing this, can limit the discourse just on inquire about articles that proposed information quality arrangement that is reasonable for coordinate execution in association. 
In reality mean to look for answers for a few particular research questions:

RQ.1: What regions of research have been shrouded in information quality research?

RQ.2: What information quality measurements are basically should have been overseen in information quality research?

RQ.3: How to efficiently oversee information quality in the association?

RQ.4: How are the evaluations of information quality being led in the association?

Here start with the huge scene of information quality research as this cause peruses to comprehend the wide ranges in information quality. In any association, information quality change isn't just constrained to the information accessible in databases yet additionally included information from different ranges, for example, sites and huge information advances. In the present scene of information quality, information assets are fluctuated and information quality execution is bound to the sort of information accessible in every datum assets. Also, for every datum assets, recognizable proof, definition and estimation of information quality measurements assumes an imperative part to guaranteeing information quality accomplishment inside the association. In RQ.2, guide peruses' thoughtfulness regarding the recognizable proof of information quality measurements and talk about a few potential issues in basic information quality measurements. I restrain my exchange just to information quality measurements that are for the most part specified in written works as basic for information quality achievement. Discourse on the basic information quality measurements gives solid substance to peruses to comprehend an exchange in RQ.3 and RQ.4. As a survey concentrate on the information quality execution inside the association, additionally talk about approaches to efficiently oversee information quality inside the association. The dialog incorporates the qualities and shortcomings of existing information quality models and technique. As information quality administration model and philosophy expected strategies to survey Data quality, proceed with an exchange in RQ.4 with more consideration given to the constraint of existing information quality appraisal techniques.

To the best of insight, examinations of accessible information quality administration model, procedures and evaluation strategy particularly for the execution inside the association has not been attempted in past investigation of writing. Recently, associations are confronting new difficulties in overseeing information quality came about because of new advances, for example, huge information and open information. Gigantic information in association can be gathered from different assets and put away in various information sorts, for example, organized, unstructured and semi-organized [5], [6]. There is a need to return to existing examination recommendations in information quality and completely talk about their impediment in taking care of different sorts of information.

\section{Research methodology}

This paper includes methodical writing survey of information quality research in associations. In light of the exploration questions, I distinguished particular subjects which are identified with information quality research region, information quality measurements, and information quality administration and information quality appraisal techniques. At that point, here build a survey system as a rule amid look into articles determination, data extraction and data union with a specific end goal to answer the exploration questions. So restrain the survey to the examination articles distributed in diaries and meeting procedures.

\section{Discussion}

\subsection{Territories of exploration in information quality}

Accomplishment of information quality execution is dictated by seven basic components including administration obligations, operation and affirmation cost, innovative work, generation, dissemination, staff administration and legitimate capacity [8]. In light of the basic elements specified before, a system of basic zones in information quality has been proposed. The proposed system featured ranges where more consideration ought to be given by specialists in accomplishing high information quality. Be that as it may, the structure is excessively perplexing despite the fact that it was very much depicted. Extemporization and disentanglement of the structure has been proposed later by describing information quality research into a few research subjects and techniques. The ad libber system proposed that information quality research advanced inside a few research subjects, for example, information quality effect, database related specialized answers for information quality, information quality in setting of software engineering and data innovation and furthermore information quality in curation [9]. Be that as it may, the creators do exclude information quality with regards to online clients including web-based social networking and sites in the proposed system. Amid the survey, found a few works in information quality that attention on quality evaluation of the web data. For instance, the appraisal of information quality in web utilizing Support Vector Regression (SVR) technique [10] and the estimation of information quality measurements in online daily paper content [11]. This demonstrates the progression of information quality research to help the extension of calculation time. In web-based social networking setting, information quality assumes a vital part to impact online client's choice [12]. As association today's use online networking for showcasing and building put stock in association with focused clients, enhancing information quality is fundamental.

Amid the survey, likewise found that information quality research has extended to help late huge information innovation. For instance, an examination has been directed to break down the effect of information estimate increase towards information quality issues [16]. As this exploration demonstrated that extensive volume of information does not ensure high information quality state, it gives open doors for scientists to investigate new techniques and ways to deal with oversee and enhance information quality in huge information condition with high information volume, high information speed and high information assortment trademark.

The headway in information quality research ranges as I told about in this paper took after information quality in its genuine application. In this way, collaboration between explore advance in information quality and this present reality application is fundamental with a specific end goal to convey top notch result. Consequently, specialized arrangement of information quality gave in the software engineering field ought to emphatically compliment the data framework field and their needs to enhance the association [17]. Future research ought to have the capacity to fill the hole between the examination done in the two fields with more concern ought to be given to the minimum investigated zone, for example, unstructured information sort from web and online networking.

\subsection{Basic measurements of information quality}

Information quality examines have been led in numerous association to recognize information quality measurements and its related properties. Nonetheless, as information quality measurements are tried and true to the setting of use, no concurrence on standard arrangement of measurements that add to high information quality can be characterized. Rather, past research recommended that information quality measurements can be portrayed utilizing multi-dimensional idea with each measurement has reliance to others keeping in mind the end goal to accomplish high information quality. For instance, an investigation has been directed to recognize connections between information exactness, information consistency, information 
culmination and information auspiciousness the built structure got from this examination can additionally be utilized to improve quality in data framework.

The ontological normal for information quality measurements is vital to give better comprehension of information quality as information quality measurements is identified with each other Information quality measurements, for example, precision, unwavering quality, convenience, fulfillment and consistency measurements can be grouped into inner and outer view [19] Each of these orders can be partitioned into information related and framework related measurements. On the other hand, information quality measurements can likewise be arranged into four classifications to be specific, characteristic, relevant, and illustrative and availability [20]. An investigation has been finished utilizing these information quality classifications to look at information quality issues in information rich association. Accordingly, it affirmed that arrangement of information quality measurements into inherent, logical, authentic and openness is legitimate [1].

Table 1: Setting of Past Examination and Strategies Utilized

\begin{tabular}{|l|l|l|}
\hline Reference & Context of Study & $\begin{array}{l}\text { Methods } \\
\text { Two-stage survey with exploratory factor } \\
\text { analysis }\end{array}$ \\
\hline$[19]$ & $\begin{array}{l}\text { Information System } \\
\text { Development }\end{array}$ & $\begin{array}{l}\text { Analysis of representation mapping, } \\
\text { comprehensive literature review }\end{array}$ \\
\hline$[21]$ & Health & $\begin{array}{l}\text { Model generated based on Financial } \\
\text { Accounting Standards Board (FASB) with } \\
\text { examples from medical domain. Evidential } \\
\text { network is then developed and assessed. }\end{array}$ \\
\hline$[22]$ & $\begin{array}{l}\text { Data producers, data } \\
\text { custodians and data } \\
\text { consumers. }\end{array}$ & $\begin{array}{l}\text { Questionnaire and assigned dimensions into } \\
\text { suggested category if more than 50\% } \\
\text { respondent agreed. }\end{array}$ \\
\hline
\end{tabular}

Information quality measurements, for example, exactness, fulfillment, consistency and presence are identified with a gathering of honesty traits [21]. Uprightness properties can be portrayed as the characteristic measurement of information quality and identified with the capacity of information to guide to the information client intrigue [21]. In correlations with illustrative consistency [20], consistency in honesty characteristic has been characterized from the information esteem point of view and not only the arrangement or portrayal of the information itself. The accessibility of information esteem, no-excess of information and created information esteem has been depicted as presence of information [21]. Respectability characteristic likewise recommended that trustworthiness and validity measurements should be rename as honesty because of the little contrasts between them.

Table 1 clarified the setting of study and strategies utilized by each examination being checked on in this paper. Here specified the setting of these investigations and strategies utilized as a part of request to help peruse to have a reasonable view on how the specialist distinguished and characterized information quality measurements, for example, information fulfillment, consistency, exactness and opportuneness. In this survey, concentrate on the measurements expressed above as these measurements being specified as basic information quality measurements [19], [23]. From an audit, study technique has been generally used to affirm the measurements and reflected information quality from its specific circumstance. Facilitate clarification on information fulfillment, information consistency, information precision and information auspiciousness will be given in the accompanying subsections.

\subsubsection{Information culmination}

Information is finished when all fundamental esteem relating to the information exist [19], [21], [22], [24]. Nonetheless, information ought to likewise have the capacity to speak to invalid esteems as sometimes, information may have no esteem related [21]. For instance, representative with unmarried status would leave the life partner name field clear. For this situation, the invalid an incentive in life partner name can't be considered as inadequate information. Understand that information may convey invalid esteem and the presence of invalid an incentive in which it is proper ought not to be consider as deficient information. Inadequate information happen when invalid esteem allotted to information that ought to has esteem. This proposes information quality appraisal process ought to have the capacity to distinguish the reason for invalid esteem found in dataset before information fulfillment can be surveyed.

\subsubsection{Information precision}

Exactness and free-of-mistake information are the primary normal for information precision [19], [21], [22]. So as to defend the exactness and the precision of information, correlations towards genuine information can be made [24]. Nonetheless, to make this definition more clearly, information exactness measurement has been ordered into semantic precision and syntactic precision [26], [27]. Syntactic exactness alludes to the closeness of the incentive towards the component of comparing definition area, though; semantic precision alludes to the closeness of the incentive towards this present reality esteem. In information quality research, the estimation of information in certifiable is difficult to be known as it required more learning about the information. Without this information can't gauge the semantic exactness. Information precision issue can occur because of many reasons. Wrong information can occur amid information section and because of methodical blunder in information generation

For instance, untrained information passage work force may inadvertently modified information esteem amid information section because of inadequate experience. For this situation, legitimate preparing and updating information passage process by including master confirmation would enhance information exactness in the association.

\subsubsection{Information opportuneness}

Information opportuneness alluded to the period of information [20]. Then again, information opportuneness can likewise be characterized as the trait of datedness [21]. Datedness characteristic included age and instability as a measure of information convenience. Then again, both research emphatically concurred that convenience and datedness ought to be measured by client with regards to application purposes. Information opportuneness is vital as the most current information can possibly be consider as high information quality [20],

Be that as it may didn't concur that information auspiciousness can be utilized as a measure of high information quality as it doesn't uncover the pertinence of that information. This is bolstered by other scientist that examined information pertinence from the viewpoint of information opportuneness [21].

Extensive accumulation of information expanded the possibility to find learning. Extensive information accumulation can be assembled trough database reconciliation, pool of machines and furthermore web data. $\mathrm{Be}$ that as it may, disseminated heterogeneous information sources as the case given and the huge volume of information may prompt the auspiciousness issue [25]. This is because of the long time expected to get to asked for information inside substantial information gathering and the many-sided quality of procedure to translate information with heterogeneous arrangement. Here accept, with suitable strategies close by, such confinements can be limited. For instance, the isolation of idle information in a different database permits database improvement and better exhibitions [29].

Here talk about information quality measurements in this paper as an establishment to the information quality administration models and philosophies which will be examined in the following segment. Strong comprehension on information quality measurements helped us to expound encourage in information quality administration models and systems. 


\subsection{Methodical administration of information quality in association}

Overseeing information quality measurements and enhancing these measurements through a methodical procedure are vital to guarantee high information quality inside the association. Thus, different investigates have been done to propose a model and approaches for methodical information quality administration. A Total Data Quality Management (TDQM) [4] has been proposed before to help the idea of 'information as an item'. With this idea, high information quality can be accomplished by imitating physical creation of astounding item. TDQM expanded Total Quality Management (TQM) structure which utilized as a part of physical generation. The strategies begin with the meaning of Information Product (IP). At this stage, the IP has its own attributes and prerequisites keeping in mind the end goal to accomplish fantastic state. At that point, the Information Quality (IQ) measurements is produced and used to gauge the IP. The estimation result is then broke down utilizing factual process control, design acknowledgment and pareto graph. Ultimately, change being made on the IP utilizing Data Assembling Investigation Framework in light of the examination done some time recently. The accessibility of different devices for result investigation as said before encourages association to actualize TDQM. Be that as it may, a few contentions happen when contrasting information creation with physical generation.

These incorporated the capacity of information to be shared among client. Besides, crude information may not land in time when required and it is hard to allocate a few quality measurements, for example, trustworthiness to physical creation. TDQM was intended for overseeing information quality in databases and current advances including huge information may restrain the utilization. This is because of the assortment of information sorts accessible in huge information. Future work is conceivable to upgrade the system by incorporating other information sources in huge information.

Information Integrity Methodology (IIM) [30] has been proposed later and plots the necessities to accomplish data honesty by tending to the establishment of information itself. Data honesty considered information capacity to meet association's vital targets. In any case, to accomplish high caliber of information, a system of data respectability ought to be satisfy. The structure included information arrangement, association capacities, information organization, design, process, approval, correspondence and system consistence. Then again, the proposed procedures included another stage in information quality administration which is to console information quality after the change procedure being made.

AIM Quality (AIMQ) show [31] involves Item and Product and Service Performance Model for Information Quality (PSP/IQ), IQA instrument to gauge data quality and data quality whole investigation strategy to enhance the data quality. Poll is utilized as a part of this model to evaluate data quality. Facilitate factual examination is then being utilized to recognize data quality issue zone. The utilized of PSP/IQ is because of the target of accomplishing great data guided by the measurements qualities specifically, inborn, illustrative, logical and availability [32].

Another case of information quality administration display is Data Quality Management Maturity Model (DQMMM). The establishment of this model is to enhance information structure quality and as the final product it would give high caliber of information [33]. In this model, structure of coordinated databases being overseen by institutionalizing its metadata Institutionalization of database metadata can be separated into a few phases, for example, coherent, physical and mapping metadata data. Other information quality administration model and systems specified before does not oversee information quality amid the reconciliation of different databases over the association. This model focused on the requirements of information incorporation with a specific end goal to improve information precision and consistency. Moreover, its capacity to guarantee high caliber of information amid database mix will be an additional esteem.

Many looks into done in information quality concentrate on organized information sort contrasted with different sorts of information, for example, semi-organized and unstructured information. In any case, in this audit, found a few models that are appropriate for either organized, semi organized or unstructured information sort. One of them is the Complete Data Quality Management (CDQM). CDQM recommend hypothetical, exact and instinctive way to deal with survey information quality [26]. It involved three phases; state recreation, appraisal and decision of ideal change process. The benefit of CDQM is the adaptability of the procedure to help organized, unstructured and semi-organized kind of information. Be that as it may, there is no characterized estimation strategy or computation to gauge information quality measurements in CDQM. Accordingly, the usage of CDQM in the association is troublesome. Condense the qualities and shortcomings of the information quality model and strategy in Table 2 in view of attributes found in the writing.

As portrayed in each of information quality administration show, information quality level should be measure and evaluate before promote examination should be possible. Following area will talked about information quality evaluation technique found amid this audit.

Table 2: Qualities and Shortcomings of Information Quality Model and Procedure

\begin{tabular}{|c|c|c|c|}
\hline Model/Methodology & Strengths & Weaknesses & Data Type \\
\hline TDQM & $\begin{array}{l}\text { Various choice } \\
\text { of tool to } \\
\text { analyze data } \\
\text { quality such as } \\
\text { statistical } \\
\text { process control, } \\
\text { pattern } \\
\text { recognition and } \\
\text { pareto chart. }\end{array}$ & $\begin{array}{l}\text { Data can be } \\
\text { shared among } \\
\text { user whereas } \\
\text { raw material } \\
\text { assigned to a } \\
\text { single } \\
\text { Product. } \\
\text { Timeliness } \\
\text { raw material } \\
\text { arrived at } \\
\text { time. } \\
\text { Believability } \\
\text { difficult to } \\
\text { compare with } \\
\text { physical } \\
\text { products. }\end{array}$ & Structured \\
\hline IIM & $\begin{array}{l}\text { Reassurance } \\
\text { phase helps } \\
\text { organization to } \\
\text { revaluate data } \\
\text { quality after } \\
\text { appropriate data } \\
\text { quality } \\
\text { improvement } \\
\text { process. }\end{array}$ & $\begin{array}{l}\text { IIM required } \\
\text { data quality } \\
\text { policy } \\
\text { creation and } \\
\text { fulfillment. } \\
\text { Thus, it takes } \\
\text { more effort } \\
\text { for the } \\
\text { organization } \\
\text { to create data } \\
\text { quality policy. }\end{array}$ & Structured \\
\hline AIMQ & $\begin{array}{l}\text { Measure data } \\
\text { quality } \\
\text { dimensions in } \\
\text { the attributes of } \\
\text { intrinsic, } \\
\text { representational, } \\
\text { contextual and } \\
\text { accessibility. }\end{array}$ & $\begin{array}{l}\text { Limited tool } \\
\text { to identify } \\
\text { information } \\
\text { quality } \\
\text { problem } \\
\text { areas. }\end{array}$ & Structured \\
\hline DQMMM & $\begin{array}{lr}\text { Manage data } \\
\text { quality during } \\
\text { database } \\
\text { integration } \\
\text { process. }\end{array}$ & $\begin{array}{l}\text { Suitable only } \\
\text { for relational } \\
\text { database. }\end{array}$ & Structured \\
\hline CDQM & $\begin{array}{l}\text { Support } \\
\text { structured, } \\
\text { unstructured and } \\
\text { semi structured } \\
\text { data type. }\end{array}$ & $\begin{array}{l}\text { Unspecific. } \\
\text { No data } \\
\text { quality } \\
\text { dimensions } \\
\text { measurement } \\
\text { and } \\
\text { calculations } \\
\text { defined in } \\
\text { CDQM. }\end{array}$ & $\begin{array}{l}\text { Structured, } \\
\text { unstructured } \\
\text { and semi } \\
\text { structured }\end{array}$ \\
\hline
\end{tabular}




\subsection{Appraisal of information quality in association}

A few strategies have been utilized to gauge and survey information quality in past research. For instance, an information quality demonstrating approach amid database plans to evaluate information quality. This examination proposed the incorporation of information quality viewpoints into database configuration by giving quality mapping produced from information quality demonstrating [34]. So trust that the reconciliation will diminish cost for anomaly's identification and quality change after database creation. Be that as it may, this approach was appropriate for organized information sort, particularly information in a social database.

Different strategies which can be utilized to evaluate information quality are Cell Level Labeling [28], Subjective and Target Information Quality Appraisal [35], Control Networks [36] and Semantic Compromise [37]. For better understanding, clarified qualities and shortcomings of each of the information quality evaluation techniques found amid this audit in Table 3. A few strategies, for example, subjective and target information quality appraisal, control frameworks and semantic compromise is appropriate for different information sorts. Be that as it may, in charge lattices techniques, the quality evaluation is depended to the accessibility of Information Product Manager (IPM). In this way, it isn't reasonable for information with high volume and high speed trademark. Then again, cell level labeling is all the more encouraging decision to evaluate information quality as it incorporated information quality necessities in database outline. $\mathrm{Be}$ that as it may, as it was plan just for social organized information sort, much works is expected to expand its use in unstructured information sort.

Table 3: Examinations on Information Quality Appraisal Techniques

\begin{tabular}{|c|c|c|}
\hline Methods & Strengths & Weaknesses \\
\hline $\begin{array}{ll}\text { Cell } & \text { Level } \\
\text { Tagging } & \end{array}$ & $\begin{array}{l}\text { Data quality being } \\
\text { integrated into database } \\
\text { design which to ensure } \\
\text { high data quality being } \\
\text { stored. This will reduces } \\
\text { costs in scanning outliers } \\
\text { and data quality } \\
\text { improvement. }\end{array}$ & $\begin{array}{l}\text { Approach taken in this } \\
\text { research is only suitable } \\
\text { for relational data. } \\
\text { However, further } \\
\text { research can be done to } \\
\text { extend the method into } \\
\text { big data area. }\end{array}$ \\
\hline $\begin{array}{l}\text { Subjective and } \\
\text { Objective Data } \\
\text { Quality } \\
\text { Assessment }\end{array}$ & $\begin{array}{l}\text { Data either structured, } \\
\text { semi structured or } \\
\text { unstructured can be assess } \\
\text { in subjective and objective } \\
\text { form. The comparisons } \\
\text { between both gives } \\
\text { broader view on data } \\
\text { quality issues. This } \\
\text { research also suggested the } \\
\text { usage of functional form } \\
\text { based on dimension to be } \\
\text { measured. }\end{array}$ & $\begin{array}{l}\text { Comparisons of } \\
\text { subjective and objective } \\
\text { result in the data quality } \\
\text { metrics only identified } \\
\text { data quality problems in } \\
\text { broad meaning. } \\
\text { Outliers' detection and } \\
\text { quality improvement are } \\
\text { still depending on the } \\
\text { data stakeholders' skills } \\
\text { and ability. }\end{array}$ \\
\hline $\begin{array}{l}\text { Control } \\
\text { Matrices }\end{array}$ & $\begin{array}{lr}\text { Support structured, semi } \\
\text { structured } \\
\text { unstructured data. }\end{array}$ & $\begin{array}{l}\text { Highly depends on the } \\
\text { availability of appointed } \\
\text { Information Product } \\
\text { Manager (IPM) to } \\
\text { assess quality. }\end{array}$ \\
\hline $\begin{array}{l}\text { Semantic } \\
\text { Reconciliation }\end{array}$ & $\begin{array}{l}\text { Support } \\
\text { heterogeneity. }\end{array}$ & $\begin{array}{l}\text { Small numbers of } \\
\text { semantic heterogeneity } \\
\text { defined in this research } \\
\text { limit its performance. }\end{array}$ \\
\hline
\end{tabular}

\section{Open exploration issues}

The progression in information quality compliments the utilizations of its answer into this present reality. The advancement since the early years of information quality research with much work concentrated to help the organized information sort in social database. A long time ahead, I expect more thought will be given to the unstructured information sorts and huge information innovation. A portion of the models and approaches being talked about in this paper have made ready towards that.
Information quality measurements are as yet ensnared to the setting of use. As what I bring up prior, discourses and research in information quality measurements was still with regards to all around organized information. In view of audit, a few information quality measurements have been talked about as basic in accomplishing high information quality; especially, information culmination, information consistency, information exactness and information auspiciousness. With regards to enormous information innovation, the estimation and appraisal strategies for these basic measurements could be distinctive as large information give monstrous volume of information with high information speed and high information assortment trademark. Here I have examined in insights about the measurements and set forward to recommendations on future research potential outcomes inside the passage. Information quality administration models, approaches and information quality evaluation strategies are the fundamental expectations in information quality research. Moreover, information quality can be overseen efficiently in the association by receiving appropriate information quality administration model and information quality appraisal techniques. Here I have examined a few accessible models, strategies and evaluation techniques in this survey but more research should be possible to fill in the hole featured in this audit, for example, the quality appraisal of unstructured information sort. In addition, all are presently in the period of huge information innovation, models, strategies and information quality evaluation techniques that can bolster unstructured information are essentially required.

\section{Conclusion}

In this audit, every one of the inquiries identified with information quality research zones, basic information quality measurements, precise information quality administration and information quality evaluation strategies have been effectively replied. As new innovation wind up noticeably accessible, information in associations is never again constrained to what are put away in the database. Different information sources, for example, site and online networking have turned out to be critical to associations in advertising and building association with their focused on clients. In this audit, examined on the developments of research zone in information quality to help the necessities in new innovation period. Additionally recognized four basic information quality measurements including information fulfillment, information consistency, information precision and information convenience. These basic information quality measurements are imperative and ought to be given most elevated need in overseeing information quality inside the association. So as to deliberately oversee information quality inside the association, existing information quality administration model and strategies, for example, TDQM, IIM and AIMQ can be received. Receiving existing information quality administration model and approaches may expect upgrade to help different information sources particularly in unstructured information. Information quality evaluation is one of the imperative exercises in efficient administration of information quality. In this survey, looked at qualities and shortcomings of accessible strategies for information quality appraisal inside the association.

Thusly, this survey proposes future thought for information quality research in association as an open research issues. Future research bearing in association setting should put more exertion in overseeing information nature of unstructured information from site, web-based social networking and enormous information.

\section{References}

[1] Strong DM, Lee YW \& Wang RY, "Data Quality in Context", Communications of the ACM, Vol.40, No.5, (1997), pp.103-110.

[2] Lee YW \& Strong DM, "Knowing-Why About Data Processes and Data Quality", Journal of Management Information Systems, Vol.20, No.3, (2003), pp.13-39. 
[3] Levitin AV \& Redman TC, "Data as a resource: properties, implications, and prescriptions", Sloan Management Review, Vol.40, (1998), pp.89-101.

[4] Wang RY, "A product perspective on total data quality management", Communications of the ACM, Vol.41, No.2, (1998), pp.58-65.

[5] Liu J, Li J, Li W \& Wu J, "Rethinking big data: A review on the data quality and usage issues", ISPRS Journal of Photogrammetry and Remote Sensing, Vol.115, (2016), pp.134-142.

[6] Sadiq S \& Indulska M, "Open data: Quality over quantity", International Journal of Information Management, Vol.37, No.3, (2017), pp.150-154.

[7] Kitchenham B, Pearl Brereton O, Budgen D, Turner M, Bailey J \& Linkman S, "Systematic literature reviews in software engineering - A systematic literature review", Information and Software Technology, Vol.51, No.1, (2009), pp.7-15.

[8] Wang RY, Storey VC \& Firth CP, "A framework for analysis of data quality research", IEEE Transactions on Knowledge and Data Engineering, Vol.7, No.4, (1995), pp.623-640.

[9] Madnick SE, Wang RY, Lee YW \& Zhu H, "Overview and Framework for Data and Information Quality Research", Journal of Data and Information Quality, Vol.1, No.1, (2009), pp.1-22.

[10] Dalip DH, Gonçalves MA, Cristo M \& Calado P, "Automatic Assessment of Document Quality in Web Collaborative Digital Libraries", Journal of Data and Information Quality, Vol.2, No.3, (2011), pp.1-30.

[11] Rajakumari SB, "Data Quality Mining in Electronic News Paper", Indian Journal of Science and Technology, Vol.7(S5), (2014), pp.47-50.

[12] Chen JV, Su B \& Widjaja AE, "Facebook C2C social commerce: A study of online impulse buying", Decision Support Systems, Vol.83, (2016), pp.57-69.

[13] Xiao Y, Lu LYY, Liu JS \& Zhou Z, "Knowledge diffusion path analysis of data quality literature: A main path analysis", Journal of Informetrics, Vol.8, No.3, (2014), pp.594-605.

[14] Marotta A \& Delgado A, "Data Quality Management in Web Warehouses using BPM", ICIQ, (2016).

[15] Helfert M \& Ge M, "Big Data Quality-Towards an Explanation Model in a Smart City Context", ICIQ, (2016).

[16] Woodall AP, Borek A, Gao J, Oberhofer M \& Koronios A, “An Investigation of How Data Quality is Affected by Dataset Size in the Context of Big Data Analytics", Proceedings of the International Conference on Information Quality, (2014).

[17] Sadiq S, Yeganeh N \& Indulska M, "20 years of data quality research: themes, trends and synergies", Proceedings of the Twenty-Second Australasian Database Conference, Vol.115, (2011), pp.153-162.

[18] Hassany P, Panahy S, Sidi F, Affendey LS, Jabar MA, Ibrahim H \& Mustapha A, "A Framework to Construct Data Quality Dimensions Relationships", Indian Journal of Science and Technology, Vol.6, No.5, (2013), pp.4421-4431.

[19] Wand Y \& Wang RY, "Anchoring data quality dimensions in ontological foundations", Communications of the ACM, Vol.39, No.11, (1996), pp.86-95.

[20] Wang R \& Strong D, "Beyond accuracy: What data quality means to data consumers", Journal of management information systems, Vol.12, No.4, (1996), pp.5-33.

[21] Bovee M, Srivastava RP \& Mak B, "A conceptual framework and belief-function approach to assessing overall information quality", International Journal of Intelligent Systems, Vol.18, No.1, (2003), pp.51-74.

[22] Kahn BK, Strong DM \& Wang RY, "Information quality benchmarks: product and service performance", Communications of the ACM, Vol.45, No.4, (2002), pp.184-192.

[23] Ballou DP \& Pazer HL, "Modeling Data and Process Quality in Multi-Input, Multi-Output Information Systems", Management Science, Vol.31, (1985), pp.150-163.

[24] Jayawardene V, Sadiq S \& Indulska M, "An Analysis of Data Quality Dimensions", ITEE Technical Report No. 2013-01, Vol.1,(2013), pp.1-32.

[25] Strong DM, Lee YW \& Wang RY, "10 potholes in the road to information quality", Computer, Vol.30, No.8, (1997), pp.38- 46.

[26] Batini C, Cappiello C, Francalanci C \& Maurino A "Methodologies for data quality assessment and improvement", ACM Computing Surveys, Vol.41, No.3, (2009).

[27] Batini C \& Scannapieca M, "Data Quality", Springer Berlin Heidelberg, (2006).

[28] Wang RY, Reddy MP \& Kon HB, "Toward quality data: An attribute-based approach", Decision Support Systems, Vol.13, No.3-4, (1995), pp. 349-372.
[29] Gi Lee S, Lee B \& Jeong H, "A Study on the Problem Analysis and Improvement Plan of the Data Quality Management System of National R\&D Data", Indian Journal of Science and Technology, Vol.8, No.23, (2015).

[30] Surendar, A., M. Kavitha, and V. Saravanakumar. "Proactive model based testing and evaluation for component-based systems." International Journal of Engineering \& Technology 8.1.1 (2018): 74-77.

[31] Lee YW, Strong DM, Kahn BK \& Wang RY, "AIMQ: a methodology for information quality assessment", Information \& Management, Vol.40, No.2, (2002), pp.133-146.

[32] Sidi F, Shariat Panahy PH, Affendey LS, Jabar MA, Ibrahim H \& Mustapha A, "Data quality: A survey of data quality dimensions", International Conference on Information Retrieval \& Knowledge Management, (2012), pp.300-304.

[33] Ryu KS, Park JS \& Park JH, "A Data Quality Management Maturity Model”, ETRI Journal, Vol.28, No.2, (2006), pp.191-204

[34] Wang RY, Kon HB \& Madnick SE, "Data Quality Requirements Analysis and Modeling", Ninth International Conference on Data Engineering, (1993).

[35] Pipino LL, Lee YW \& Wang RY, "Data quality assessment", Communications of the ACM, Vol.45, No.4, (2002). 